\title{
POPULISMO DE IZQUIERDA EN EUROPA: UNA COMPARACIÓN ENTRE PODEMOS Y LA FRANCIA INSUMISA
}

\section{Left-Wing Populism in Europe: A Comparison between Podemos and France Insoumise}

\author{
PABLO CASTAÑO \\ Universidad Autónoma de Barcelona \\ pablo.castano@uab.cat
}

Cómo citar/Citation

Castaño, P. (2019).

Populismo de izquierda en Europa: una comparación entre

Podemos y la Francia Insumisa.

Revista de Estudios Políticos, 184, 41-65.

doi: https://doi.org/10.18042/cepc/rep.184.02

\section{Resumen}

Los partidos populistas de izquierda han adquirido una creciente relevancia política en Europa desde la crisis económica de 2008, pero han sido menos estudiados que los partidos populistas de derecha radical. La presente investigación contribuye a colmar este vacío al realizar una comparación entre Podemos y FI, dos casos paradigmáticos de partidos populistas de izquierda. Se analizan dos dimensiones: el discurso y la organización interna de ambos partidos. El artículo se basa en el análisis cualitativo del contenido de documentos programáticos y organizativos publicados por ambos partidos e intervenciones públicas de sus líderes durante la etapa de surgimiento y consolidación de cada partido. El análisis permite alcanzar dos conclusiones. Primera: Podemos y FI tienen un discurso inclusivo en las dimensiones simbólica, material y política (Mudde y Rovira Kaltwasser, 2013) — lo que los distingue de la derecha radical populista-. Segunda: cada partido tiene una estructura diferente, lo que sugiere que el populismo de izquierda no implica un modelo organizativo determinado.

\section{Palabras clave}

Populismo; izquierda; partidos políticos; Podemos; Francia Insumisa; análisis del discurso; programas electorales. 


\begin{abstract}
Left-wing populist parties have become increasingly central to European politics since the 2008 economic crisis, but have been analysed less often than radical right-wing populist parties. This research contributes to filling this gap through a comparison of Podemos and France Insoumise, two paradigmatic cases of left-wing populist parties. Two dimensions are analysed: the discourse and the inner organisation of the parties. The article is based on qualitative content analysis of policy and organisational documents published by both parties, and on public interventions made by their respective leaders during the periods of emergence and consolidation of each party. The analysis allows us to reach two conclusions. First, Podemos and France Insoumise both promote discourses that are inclusive in their symbolic, material and political dimensions (Mudde and Rovira Kaltwasser, 2013) - which allows us to distinguish them from the radical populist right. Second, the two parties have different structures, which suggests that left-wing populism does not necessarily imply a specific organisational model.
\end{abstract}

\title{
Keywords
}

Populism; left; political parties; Podemos; France Insoumise; discourse analysis; electoral programs. 


\section{SUMARIO}

I. MARCO TEÓRICO: 1. La definición del populismo de izquierda. 2. Populismo y democracia. II. EL PUEBLO CONTRA LA CASTA: LOS DISCURSOS POPULISTAS DE PODEMOS Y LA FRANCIA INSUMISA: 1. El origen del discurso populista. 2. La definición de la élite y el pueblo. 3. El uso de símbolos nacionales y referencias históricas. 4. Semejanzas y diferencias entre el discurso populista de Podemos y Fl. III. LA ESTRUCTURACIÓN DEL POPULISMO DE IZQUIERDA: 1. El origen del modelo organizativo de Podemos y Fl. 2. Entre autoorganización y jerarquía: los modelos organizativos de Podemos y FI. 3. La estructura de Podemos y FI: parecidos y semejanzas. IV. CONCLUSIONES. BIBLIOGRAFíA.

Una «ola populista» parece estar recorriendo Europa y Estados Unidos en los últimos años ${ }^{1}$. Como consecuencia, el populismo está recibiendo una creciente atención de la literatura, especialmente los partidos de «derecha radical populista» (Mudde, 2016; Hernández-Carr, 2011a, 2011b). Sin embargo, la crisis financiera y económica iniciada en 2008 también facilitó la aparición o el crecimiento electoral de un grupo de partidos populistas de izquierda, como Syriza en Grecia, FI en Francia, el Partido Laborista británico liderado por Jeremy Corbyn en Reino Unido y Podemos en España (Uribe Otalora, 2017). A pesar de la considerable importancia electoral y política de estos partidos, la literatura sobre ellos es todavía escasa, por lo que las características específicas de estas organizaciones son poco conocidas. El presente artículo tiene el objetivo de avanzar en el conocimiento de los rasgos distintivos de los partidos populistas de izquierda en el contexto europeo. Para ello, realizaré un análisis empírico comparado de dos partidos que en principio parecen ser tipos ideales del populismo de izquierda: Podemos y FI (FI).

El ascenso electoral de Podemos entre 2014 y 2015 atrajo el interés de numerosos investigadores (Marzolf y Ganuza, 2016; Kioupkiolis, 2016; Rodríguez López, 2016; Casero-Ripollés et al., 2017; Franzé, 2017; Uribe Otalora, 2017), pero todavía hay pocos artículos académicos sobre FI (Birnbaum, 2017; Fassin, 2017; Fourquet, 2017). Existe algunos estudios comparados entre partidos populistas europeos (Borreca, 2014; Kioupkiolis y Katsambekis, 2018; Prat, 2015; Semenzin, 2015), pero muy pocos analizan partidos populistas de

Al autor le gustaría agradecer los comentarios de Guillermo Fernández Vázquez y Julio Martínez-Cava sobre el primer borrador del artículo. 
izquierda y ninguna investigación se ha centrado todavía en los casos de Podemos y FI, una laguna que el presente artículo pretende contribuir a colmar. Para la presente investigación, se consideran como partidos populistas de izquierda a aquellos que cumplen las siguientes características:

a) Una ideología basada en la división de la sociedad entre la élite y el pueblo y una concepción maniquea en la que el pueblo es "puro» y la élite "corrupta», y la voluntad popular es central (Mudde, 2004).

b) Un liderazgo carismático (Laclau, 2005).

c) Defensa de políticas económicas keynesianas opuestas a las políticas de austeridad (dimensión material) (Mudde y Rovira Kaltwasser, 2013).

d) Defensa de mecanismos de participación política directa (dimensión política). (ibid.).

e) Definición del pueblo en términos no étnicos o culturales (dimensión simbólica) (ibid.).

El análisis se centrará en dos dimensiones de Podemos y FI: su discurso populista y su organización interna (o estructura). En relación con el discurso, se compararán tres dimensiones: a) el origen del discurso de cada partido; b) la definición de la élite y el pueblo, y c) el uso de símbolos nacionales y referencias históricas. En lo que respecta a la organización interna, se analizarán dos dimensiones de ambos casos de estudio: a) el origen del modelo organizativo adoptado, y b) la estructura del partido. El artículo tiene tres partes: marco teórico, análisis del discurso de Podemos y FI, y análisis de la organización interna de ambos partidos.

El artículo está basado en el análisis cualitativo de declaraciones públicas de líderes de ambos partidos y documentos programáticos y organizativos publicados por ambas formaciones (programas electorales y diversos textos extraídos de sus páginas web). Los documentos han sido seleccionados con el método de "muestreo intencionado» (Lindekilde, 2014), que permite centrarse en los documentos más relevantes para los fines de la investigación dentro de un marco temporal determinado. El análisis se centra en los ańos 2014-2016 para Podemos y la etapa 2017-2018 en el caso de FI, ya que son los periodos en los que se establecieron las características principales del discurso y la organización interna de ambos partidos. Por tanto, las declaraciones de los líderes de ambos partidos corresponden a los periodos seńalados, y en ambos casos se analiza el primer programa electoral de cada partido en unas elecciones generales (los comicios de 2015 y 2016 en el caso de Podemos —el partido presentó un programa muy similar a ambas elecciones-y las elecciones presidenciales y legislativas de 2017 en el caso de FI). Aunque en los dos 
casos el análisis se centra en la fase de surgimiento y consolidación del partido, también se incluye una breve referencia al segundo congreso de Podemos, celebrado en 2017, para completar el análisis de su modelo organizativo.

\section{MARCO TEÓRICO}

\section{LA DEFINICIÓN DEL POPULISMO DE IZQUIERDA}

El término "populismo» es un concepto controvertido dentro de la ciencia política. Para algunos autores se trata de una "estrategia» (De la Torre y Peruzzotti, 2008: 18), mientras que para otros es un «estilo político» (Freidenberg, 2008), una «intervención» (Panizza, 2008) o incluso un "experimento» (Frei y Rovira Kaltwasser, 2008: 128-129). Sin embargo, la mayoría de los autores que trabajan sobre el populismo en Europa consideran el populismo como una thin ideology, una "ideología ligera» que siempre se combina con otras ideologías (Mudde, 2004; Mudde y Rovira Kaltwasser, 2013; Uribe Otalora, 2017). Los tres elementos de esta «ideología ligera» son la división de la sociedad entre la élite y el pueblo, una concepción maniquea en la que el pueblo es "puro» y la élite "corrupta» y la centralidad de la voluntad popular (Mudde, 2004: 543; Mudde y Rovira Kaltwasser, 2013: 150-151). Además, es conveniente añadir a la definición de Mudde (2004) la importancia que autores como Laclau (2005) atribuyen al líder carismático en la construcción populista. En la concepción de Laclau, el populismo se basa en el establecimiento de una cadena de equivalencias entre demandas sociales dispares e insatisfechas por el sistema político. El líder es un factor unificador clave en esta construcción, como explica el autor argentino: «La lógica de la equivalencia conduce a la singularidad, y esta a la identificación de la unidad del grupo con el nombre del líder» (ibid:: 130). En palabras de Thomassen (2016: 166), el «líder a la vez representa una indignación existente y hace esta indignación presente (la "representa") en los medios de comunicación y las instituciones políticas».

En este artículo se concibe el populismo como una "ideología ligera», ya que esta perspectiva permite definir al conjunto de partidos populistas (de izquierda y de derecha) y diferenciarlos del resto de partidos. En este sentido, Mudde y Rovira Kaltwasser (2013) subrayan que la definición del populismo que defienden permite excluir a la mayoría de partidos existentes, ya que son elitistas o pluralistas. Según estos autores, los partidos elitistas comparten con el populismo la división entre pueblo y élite, pero consideran que la élite es superior al pueblo "en términos culturales, intelectuales y morales». Por su parte, los pluralistas «asumen que la sociedad está compuesta por múltiples 
grupos sociales con ideas e intereses diferentes» (ibid.: 152). La importancia del establecimiento de una línea que separa al pueblo de la élite también está presente en la teorización del populismo propuesta por Ernesto Laclau y Mouffe (2001), Laclau (2005) y Mouffe (2005), los principales teóricos de referencia de Podemos y FI.

Mudde y Rovira Kaltwasser (2013) han precisado la definición de populismo de Mudde (2004) estableciendo una distinción entre populismo «inclusivo» (inclusionary) y "excluyente» (exclusionary), que es muy útil para el análisis empírico de partidos populistas. Estos autores tienen en cuenta tres dimensiones para analizar empíricamente el carácter incluyente o excluyente de los partidos populistas: material, política y simbólica. La dimensión material se refiere a «la distribución de los recursos del Estado - tanto monetarios como no monetarios- entre los grupos específicos de la sociedad» (Mudde y Rovira Kaltwasser, 2013: 158). Es decir, una perspectiva inclusiva en la dimensión material implica que los grupos más vulnerables reciben una atención particular por parte del Estado (dentro de una lógica de justicia social), mientras que si se aplica una perspectiva excluyente ciertos grupos son excluidos de los recursos públicos (como veremos, se trata generalmente de minorías nacionales o étnicas). En relación con la dimensión política, un partido inclusivo desarrollaría medidas para promover la participación política de los grupos más discriminados o previamente excluidos, mientras que un partido excluyente impediría la participación completa de ciertos grupos en la vida política. Finalmente, los partidos populistas incluyentes en la dimensión simbólica tienen una concepción del «pueblo» que no excluye a ningún grupo social (para ellos, el «pueblo» es toda la sociedad excepto la élite, que es definida como una oligarquía políticoeconómica, pero nunca en términos esencialistas). Por el contrario, los partidos populistas excluyentes en la dimensión simbólica no incluyen en su concepto de "pueblo" a todos los colectivos que forman la sociedad del país, sino que excluyen a ciertos sectores, normalmente definidos por sus rasgos étnicos o culturales (la mayoría de los partidos populistas de derecha radical europeos han elegido la islamofobia y el rechazo de la inmigración como temas prioritarios).

Mudde y Rovira Kaltwasser han aplicado estas categorías al análisis empírico de dos partidos populistas latinoamericanos (el MAS boliviano y el PSUV venezolano) y a dos partidos europeos (el FN francés y el FPÖ austriaco), llegando a la conclusión de que los partidos latinoamericanos practican un populismo inclusivo, mientras que el populismo del FN y FPÖ es excluyente (ibid.: 168). En el contexto de la Gran Depresión europea, se puede argumentar que las tres dimensiones del populismo inclusivo propuestas por Mudde y Rovira Kaltwasser adoptarían el siguiente contenido específico: la defensa de políticas económicas keynesianas opuestas a las políticas de austeridad 
(dimensión material); la proposición de mecanismos de participación política directa (dimensión política), y la definición del pueblo en términos no étnicos ni culturales (dimensión simbólica). Como se ha avanzado en la introducción en el presente artículo se consideran como partidos populistas de izquierda a aquellos que cumplen las siguientes características:

a) Una ideología basada en la división de la sociedad entre la élite y el pueblo, una concepción maniquea en la que el pueblo es "puro» y la élite "corrupta», y la voluntad popular es central (Mudde, 2004).

b) Un liderazgo carismático (Laclau, 2005).

c) Defensa de políticas económicas keynesianas opuestas a las políticas de austeridad (dimensión material) (Mudde y Rovira Kaltwasser, 2013).

d) Defensa de mecanismos de participación política directa (dimensión política). (ibid.).

e) Definición del pueblo en términos no étnicos o culturales (dimensión simbólica) (ibid.).

Esta definición se aplicará al análisis comparado de los discursos de Podemos y FI.

\section{POPULISMO Y DEMOCRACIA}

Los debates sobre la relación entre populismo y democracia constituyen una de las ramas más ricas de la literatura sobre populismo, y es necesaria para el análisis de la organización interna de los partidos populistas de izquierda que se llevará a cabo en el presente artículo. Para algunos autores, existe una contradicción fundamental entre populismo y democracia porque la división de la sociedad en «dos campos irreconciliables» constituye una amenaza para el pluralismo (Peruzzotti, 2013). En este sentido, ciertos autores han identificado una tendencia de los partidos populistas hacia la concentración del poder en las manos del jefe del Ejecutivo. Esta concentración del poder y la «impaciencia [de los líderes populistas] con las formalidades del proceso político» (Arditi, 2011) se traducirían en tentativas de controlar el Poder Judicial (Gamarra, 2008) o los medios de comunicación (Repoll, 2010). Otros autores consideran que el populismo puede «revigorizar» la política democrática (Thomassen, 2016) y que es perfectamente compatible con la democracia liberal, como lo demostrarían los esfuerzos realizados por ciertos Gobiernos populistas de izquierda latinoamericanos para responder a las demandas de las víctimas de violaciones de derechos humanos durante las dictaduras militares (Laclau, 2005). Sin embargo, la posición más frecuente en la literatura es que existe una relación ambigua entre 
populismo y democracia liberal (Frei y Rovira Kaltwasser, 2008; Pasquino, 2008). De acuerdo con esta postura, existen tensiones entre el populismo y las instituciones intermedias de la democracia liberal, pero el populismo también ha logrado integrar en la vida política a grandes sectores de la población que estaban previamente excluidos (Crabtree, 1999) y ha promovido la democracia directa mediante la celebración de frecuentes referendos y la introducción de mecanismos de participación ciudadana (De la Torre, 2013). Panizza (2008) afirma que es imposible encontrar un modelo general de relación entre populismo y democracia, mientras que otros autores consideran que el populismo es a la vez una amenaza y un correctivo para la democracia (Weyland et al., 2010; Levitsky y Roberts, 2011; Castaño, 2018). Por otro lado, no existe ningún trabajo que se centre específicamente en la organización interna de los partidos populistas y que permita aplicar los debates sobre populismo y democracia al análisis empírico de las organizaciones populistas. El análisis comparado entre Podemos y FI pretende contribuir a colmar este vacío en la literatura.

\section{EL PUEBLO CONTRA LA CASTA: LOS DISCURSOS POPULISTAS DE PODEMOS Y LA FRANCIA INSUMISA}

Tanto Podemos como FI han sido influidos de forma determinante por el MAS, el PSUV y el partido populista ecuatoriano Alianza País. Además, ambos partidos comparten la centralidad de la figura del líder (Pablo Iglesias en Podemos y Jean-Luc Mélenchon en el caso de FI), un rasgo típico de los partidos populistas. A pesar de tener en común estas fuentes de inspiración, los contextos políticos que rodearon la creación de Podemos y FI han sido diferentes, lo que podría explicar la existencia de ciertas diferencias entre los dos tipos de discurso populista. En esta sección se compararán tres dimensiones del discurso de ambos partidos: a) el origen del discurso; b) la definición de la élite y el pueblo, y c) el uso de símbolos nacionales y referencias históricas.

\section{EL ORIGEN DEL DISCURSO POPULISTA}

La irrupción de Podemos en la escena política española estuvo precedida por el Movimiento 15M o "movimiento de los indignados», cuya influencia sobre Podemos fue tan intensa que ciertos analistas consideran que «sin el 15M, Podemos no habría existido» (Grueso y Sánchez, 2016). Según el análisis de Errejón (2015), el discurso del 15M contenía destacados elementos populistas. En efecto, no fue Podemos quien introdujo en España la división discursiva del campo político entre «los de arriba" y "los de abajo» (en lugar de la división tradicional entre derecha e izquierda), sino el $15 \mathrm{M}$. El «movimiento de 
las plazas» comenzó con una manifestación convocada el 15 de mayo de 2011 por el colectivo Democracia Real Ya, cuyo eslogan fue "No somos mercancías en manos de políticos y banqueros», un lema que señalaba a la oligarquía política y financiera como culpable de la crisis. El movimiento Juventud sin Futuro también desplegó un discurso que trazaba una división radical entre el pueblo y la élite, que a menudo era identificada con el régimen político fundado por la Constitución de 1978. Así, Juventud sin Futuro apoyó la huelga general del 14 de noviembre de 2012 con el lema «Huelga del $99 \%$ contra régimen del $1 \% »$. En junio de 2011, el $81 \%$ de los espańoles afirmaba que el Movimiento $15 \mathrm{M}$ «tenía razón» (Garea, 2011). Durante los meses siguientes, entre el 10 y el $20 \%$ de la población española participó en las acciones del movimiento, según un estudio del Centro de Investigaciones Sociológicas ${ }^{2}$ y el análisis de diversas fuentes efectuado por Adell Argilés (2011).

Sin embargo, el movimiento no consiguió detener las políticas de austeridad impulsadas por los Gobiernos sucesivos del Partido Socialista Obrero Español (PSOE) y el Partido Popular (PP), después de que el presidente socialista José Luis Rodríguez Zapatero decidiese en 2010 el mayor recorte presupuestario de la era democrática. En este contexto de frustración y agotamiento para los movimientos sociales, en enero de 2014 un grupo de intelectuales y activistas de izquierda presentó en Madrid un manifiesto en el que proponían la constitución de una candidatura ciudadana para las elecciones europeas de mayo, llamada Podemos. Como han explicado Marzolf y Ganuza (2016), el nuevo partido utilizó en la competición electoral la influencia que el movimiento $15 \mathrm{M}$ había tenido sobre el discurso dominante en la sociedad española, sobre todo a través del uso del término "casta" para designar a las élites contra las que Podemos construyó su discurso político. En Podemos, la influencia discursiva del 15M se ha combinado con la de partidos populistas de izquierda latinoamericanos como el MAS de Evo Morales o el PSUV de Hugo Chávez — dirigentes de Podemos trabajaron como asesores para ambos Gobiernos y el que fue secretario político de Podemos entre 2014 y 2017, Ínigo Errejón, analizó en su tesis doctoral la estrategia discursiva del MAS (Errejón, 2011)—.

El origen del discurso populista de FI es diferente del de Podemos, ya que es más bien el fruto de la evolución política e intelectual de Jean-Luc Mélenchon. Es cierto que en Francia también hubo un "movimiento de las plazas» (Nuit debout o Noche en Pie). Sin embargo, este movimiento tuvo una magnitud muy inferior a la del 15M en España (Castaño, 2016), no tuvo un discurso populista (se centró más bien en la «convergencia de luchas») y además comenzó en marzo

2 Centro de Investigaciones Sociológicas (2011). Ficha del estudio 2920. Disponible en: https://bit.ly/2TlAGUJ. 
de 2016, cuando Mélenchon ya defendía públicamente un discurso populista. El líder de FI ha explicado su evolución política desde la izquierda alternativa al populismo de izquierda en libros como ; Que se vayan todos! (2010) y La era del pueblo (2014). En estas obras Mélenchon defiende que el motor del cambio político ya no es la clase obrera - como ha defendido tradicionalmente la izquierda comunista y poscomunista—, sino el «pueblo urbano». Según Mélenchon, este nuevo actor político tiene «un terreno de expresión, el espacio público, así como una estrategia de toma del poder, la revolución ciudadana» (Gales, 2015). En efecto, Jean-Luc Mélenchon ha tomado del expresidente ecuatoriano Rafael Correa el lema «La revolución ciudadana» y ha reproducido el eslogan «iQue se vayan todos!» de las caceroladas y movilizaciones antineoliberales que se produjeron en Argentina tras el estallido de la crisis financiera de 2001. Por lo tanto, el líder «insumiso» comparte con Pablo Iglesias y otros portavoces de Podemos la influencia del populismo de izquierda latinoamericano.

\section{LA DEFINICIÓN DE LA ÉLITE Y EL PUEBLO}

Una de las claves de la irrupción de Podemos en la escena política española fue su discurso contra la "casta». A través del uso repetido de este término, Pablo Iglesias y los demás portavoces del partido denunciaron la existencia de una élite política y económica cuyos intereses serían —según el discurso de Podemos- opuestos a los de la mayoría de la población (el «pueblo»); la casta sería la culpable de la profunda crisis económica y social que España sufre desde 2009. Unos días después de las elecciones europeas de 2014, el líder de Podemos afirmaba que «la casta quiere mantener un sistema que nos lleva al desastre» ${ }^{3}$. Otros términos que han aparecido en el discurso de Podemos para definir a la élite son «los privilegiados» ${ }^{4} \mathrm{y}$, sobre todo, «los de arriba». Por ejemplo, Pablo Iglesias utilizó esta última expresión en su discurso del 31 de enero de 2015, pronunciado ante las cerca de 100000 personas que participaron en la Marcha del Cambio convocada por Podemos 5 .

En relación con la definición del pueblo, Podemos adopta una perspectiva inclusiva en la dimensión simbólica (Mudde y Rovira Kaltwasser, 2013), en la que las minorías étnicas y nacionales residentes en España son incluidas

3 Iglesias, P. (2014). La casta quiere mantener un sistema que nos lleva al desastre. La Vanguardia, Disponible en: https://bit.ly/2JsUYvU.

4 Errejón, Í. (2016). Los privilegiados tienen mucho poder, pero en Canarias más. Canarias 7, 14-6-2016. Disponible en: https://bit.ly/2UNNIMv.

5 Iglesias, P. (2015). Discurso completo de Pablo Iglesias en la «Marcha del Cambio». Youtubecom, 31-1-2015. Disponible en: https://bit.ly/2kivphS. 
de forma explícita. La concepción inclusiva del pueblo defendida por Podemos se manifiesta con particular claridad en los discursos de los líderes del partido en relación com la "patria». Pablo Iglesias aprovechó el 12 de octubre de 2016 (el festivo nacional que celebra el supuesto descubrimiento de América en $1492 \mathrm{y}$, por lo tanto, tiene fuertes connotaciones colonialistas) para explicar su noción de la patria:

Para nosotros, la patria es la gente. [...] Les decimos a nuestros hermanos latinoamericanos que estamos orgullosos de su independencia [...]. Estamos encantados de que cientos de miles de trabajadores latinoamericanos hayan venido a construir un país nuevo con nosotros ${ }^{6}$.

La lectura del programa electoral presentado a las elecciones generales de 2016 por la coalición Unidos Podemos ${ }^{7}$ — compuesta por Podemos, Izquierda Unida, Equo y otros partidos de ámbito autonómico- permite identificar numerosas propuestas que se corresponden con la defensa de políticas keynesianas y la oposición a las políticas de austeridad (dimensión material), como la subida del impuesto sobre la renta a los tramos superiores y el despliegue de un plan nacional de transición energética al que se destinaría el 1,5\% del producto interior bruto durante veinte años. Asimismo, Podemos y sus aliados propusieron la mejora o creación de mecanismos de profundización democrática (dimensión política), como la flexibilización de las condiciones para la presentación de iniciativas legislativas populares y la posibilidad de revocar los cargos electos. En conclusión, el análisis del discurso de Podemos muestra que se trata de un partido populista «incluyente» en las tres dimensiones identificadas por Mudde y Rovira Kaltwasser (2013).

Las primeras experimentaciones de Jean-Luc Mélenchon con el populismo tuvieron lugar durante la campaña por el «no» en el referéndum de 2005 sobre el Tratado Constitucional Europeo, donde Mélenchon definió a la élite con términos como "los poderosos, los importantes, los perfumados» (Gales, 2015). Más tarde, el líder de FI adoptó la palabra fetiche del primer Podemos: la "casta», que él define como «los todopoderosos financieros y sus marionetas políticas, mediáticas» ${ }^{8}$. El líder de FI ha desarrollado su

6 Iglesias, P. (2016). «Mi patria es la gente». Youtube.com, 12-10-2016. Disponible en: https://bit.ly/2r50WHI.

7 Unidos Podemos (2016). Programa electoral 2016. Disponible en: https://bit. ly/2TlT0gs.

8 Mélenchon, J. L. (2016). La caste, les primaires et la souveraineté du peuple. Youtube. com, 20-11-2016. Disponible en: https://bit.ly/2OlYvuL. 
concepción de la élite en otra entrevista, en los siguientes términos: «Mi enemigo es la oligarquía con su continuación social: la casta»" Para Mélenchon, la "casta» política y mediática es la «marioneta» de la oligarquía, en la que el mundo financiero ocupa el lugar principal. Es importante subrayar que Mélenchon incluye a los medios de comunicación en su definición de la élite de la que se considera rival, lo que está relacionado con su larga trayectoria de enfrentamientos con la prensa.

En cuanto a la definición del pueblo, FI comparte con Podemos una concepción inclusiva, no étnica. La posición de Jean-Luc Mélenchon sobre la inmigración no ha estado siempre tan clara como la de Podemos (Castaño, 2017) y ha recibido numerosas críticas de la izquierda por este motivo (Bréville, 2017). En 2012 Mélenchon pronunció un discurso explícitamente antirracista y multiculturalista unos días antes de la primera vuelta de la elección presidencial. En su libro La elección de la insumisión (Mélenchon y Endeweld, 2016) afirmó que este discurso quizá no «benefició» a su resultado electoral (11\%, inferior al $17 \%$ que preveían algunas encuestas unos días antes). Sin embargo, es mucho más probable que la caída fuese provocada por el voto útil a François Hollande, como afirmó el portavoz «insumiso» Alexis Corbière (Le Gal, 2017). Sin embargo, la orientación de FI sobre este tema evolucionó durante los últimos meses antes de la elección presidencial de abril de 2017 y su programa terminó por incluir importantes proposiciones políticas favorables a los derechos de inmigrantes y refugiados, como el final de los centros de retención de extranjeros, la regularización de todos los trabajadores sin papeles y el respeto del derecho de asilo ${ }^{10}$. Además, en el mitin celebrado en Marsella el 9 de abril de 2017, Mélenchon guardó un minuto de silencio por las cerca de 30000 personas que murieron en el Mediterráneo durante los últimos ańos cuando intentaban llegar a Europa. (Mélenchon, 2017a).

Por lo tanto, la definición del pueblo defendida por FI es radicalmente diferente de la de los partidos populistas ultranacionalistas como el Frente Nacional, que excluyen de su concepto de pueblo a los extranjeros y a los nacionales pertenecientes a ciertas minorías culturales o étnicas (los musulmanes son señalados frecuentemente como una amenaza por la extrema derecha) (Alba Rico, 2015). La concepción del pueblo de Mélenchon ha sido definida por Gales en los siguientes términos (Gales, 2015):

9 Mélenchon, J. L. (2016). Mon ennemi, c"est l"oligarchie!. L"Obs, 29-4-2016. Disponible en: https://bit.ly/2Q3gBRu.

10 La France Insoumise (2017). Respecter les migrants, régler les causes des migrations. Disponible en: https://bit.ly/2nzPtib. 
Como los franceses no tienen el mismo color de piel, la misma religión, las mismas costumbres y que incluso la lengua ya no es el menor denominador común, la Nación francesa no puede estar basada en una perspectiva étnica, religiosa o cultural. Solo el consentimiento al pacto político la define.

El partido de Jean-Luc Mélenchon propuso durante las elecciones presidenciales y legislativas de 2017 un amplio abanico de políticas económicas y sociales de tipo keynesiano cuyo principal objetivo era la lucha contra la pobreza y las desigualdades, así como mecanismos de profundización democrática como la posibilidad de revocar a cargos electos, la introducción de una cierta proporcionalidad en las elecciones legislativas y la flexibilización de los criterios para celebrar referendos (Mélenchon y La France insoumise, 2016). El análisis del discurso de FI permite calificarlo como un partido populista inclusivo en las dimensiones simbólica, material y política (Mudde y Rovira Kaltwasser, 2013), lo que constituye un punto en común fundamental con Podemos.

\section{EL USO DE SÍMBOLOS NACIONALES Y REFERENCIAS HISTÓRICAS}

Las frecuentes referencias a la patria constituyen una originalidad de Podemos en relación con la historia reciente de la izquierda española (Franzé, 2017: 230). En la campaña de las elecciones generales de junio de 2016 hubo incluso intentos de recuperar la bandera espańola actual (monárquica) por parte de los sectores más populistas de Podemos, pero se encontraron con la resistencia de gran parte de las bases del partido, cuya cultura política es republicana. Como veremos más adelante, la relación con la bandera nacional es diferente en el caso de FI. Uno de los rasgos frecuentes de los discursos populistas son las referencias a épocas históricas pasadas, que funcionan como ideal político al que aspirar. En el caso de Podemos, la Segunda República española jugó este papel de referente histórico al menos durante el año 2014, cuando las menciones a la República tuvieron una presencia considerable en el discurso del partido (Franzé, 2017). El discurso de Podemos presentaba la Segunda República como «un momento de protagonismo popular-democrático» (Franzé, 2017: 228).

Igual que en el caso de Podemos, las referencias a la patria son frecuentes en el discurso de FI, lo que supone una ruptura con las claves discursivas más frecuentes de la izquierda radical francesa. A lo largo de la campaña presidencial de 2017 La Internacional (el himno socialista) fue paulatinamente sustituido por La Marsellesa (el himno nacional francés) y el partido llegó a retirar a las personas que asistían a sus mítines las banderas rojas, sustituyéndolas por banderas francesas. La resistencia de la militancia de FI a esta «nacionalización» de la campaña fue limitada, en parte porque La Marsellesa tiene un origen revolucionario 
(frente al origen monárquico del himno español) y la bandera francesa está menos asociada al nacionalismo conservador que la española. Por otro lado, el discurso populista de Jean-Luc Mélenchon está alimentado por dos periodos históricos: la etapa jacobina de la Revolución francesa y el republicanismo social del siglo Xx, encarnado por la figura de Jean Jaurès (Gales, 2015). Sin embargo, hay pocas referencias al Frente Popular que gobernó Francia en los años treinta, una referencia histórica muy apreciada por el Partido Comunista francés. Por lo tanto, vemos cómo Mélenchon también se diferencia de la izquierda tradicional en la selección de los periodos históricos que le sirven como modelo.

\section{SEMEJANZAS Y DIFERENCIAS ENTRE EL DISCURSO POPULISTA DE PODEMOS Y LA FRANCIA INSUMISA}

El análisis comparado de los discursos de Podemos y FI muestra la gran proximidad que existe entre ambos partidos, que nos lleva a incluir a ambas formaciones en la categoría del populismo de izquierda, tal y como ha sido definida en la introducción del presente artículo. Existe, sin embargo, una diferencia de intensidad en la defensa de una definición inclusiva del pueblo, ya que los portavoces de Podemos han explicitado a menudo la pertenencia de los migrantes residentes en España a su idea de pueblo, lo que no ha sido expresado de una forma tan explícita por los portavoces de FI. No obstante, el programa electoral para las elecciones presidenciales de 2017 clarificó la posición de FI sobre este tema, confirmando su pertenencia a la categoría del populismo «inclusivo» en la dimensión simbólica. Existen otras dos diferencias relevantes entre los discursos de ambas formaciones. En primer lugar, el discurso de Podemos durante el año 2014 incluyó frecuentes referencias a la Segunda República española (que se redujeron en los años siguientes), mientras que Mélenchon se refiere a menudo a la etapa jacobina de la Revolución francesa y al republicanismo social de Jean Jaurès. En segundo lugar, FI ha adoptado en sus actos los símbolos nacionales franceses (himno y bandera), mientras que Podemos no lo ha hecho, debido a la asociación de estos símbolos con la monarquía y posturas políticas conservadoras. Las dos diferencias señaladas están relacionadas con la cultura política dominante en cada país y la diferente evolución histórica de la izquierda en Espańa y Francia.

\section{LA ESTRUCTURACIÓN DEL POPULISMO DE IZQUIERDA}

El objetivo de esta sección es realizar un análisis comparado de la organización interna de Podemos y FI, a través de dos dimensiones: el origen del modelo organizativo adoptado y la estructura del partido. 


\section{EL ORIGEN DEL MODELO ORGANIZATIVO DE PODEMOS Y LA FRANCIA INSUMISA}

Las características principales de la organización interna de Podemos derivan de dos orígenes contradictorios: la herencia horizontalista del movimiento $15 \mathrm{M}$ y la decisión de la dirección del partido de priorizar la competición electoral sobre cualquier otro objetivo político. Poco después de la presentación de Podemos en Madrid en enero de 2014, sus promotores lanzaron una recogida de firmas para apoyar su candidatura a las elecciones europeas de mayo, y obtuvieron 50000 firmas en solo un día. Se abrió una cuenta de Facebook y durante los meses siguientes surgieron cientos de "círculos» en todo el territorio español. Marzolf y Ganuza han analizado cómo la importancia de los círculos en la primera época de Podemos estaba ligada a la herencia política del movimiento $15 \mathrm{M}$, uno de cuyos principales medios de acción fue la ocupación de plazas y la celebración de asambleas ciudadanas: «Los círculos reemplazaban sin distorsiones el asambleísmo del $15 \mathrm{M}$, pero integrando esta metodología en un proceso político formal» (Marzolf y Ganuza, 2016: 102). La importancia de la participación ciudadana en la práctica política de Podemos se manifestó también en el método para la composición de la lista del partido para las elecciones europeas de mayo de 2014: los candidatos fueron seleccionados mediante primarias telemáticas y abiertas a toda la ciudadanía - para poder votar solo era necesario inscribirse en la web del partido-.

Sin embargo, el carácter horizontal de Podemos se vio cuestionado a partir del congreso fundacional de Podemos, la Asamblea Ciudadana de Vistalegre (Madrid), en noviembre de 2014 (conocida como «Vistalegre I»). Como se explicará en detalle más adelante, desde entonces Podemos adoptó una estructura jerárquica similar a la de los partidos tradicionales, aunque con ciertos elementos innovadores. La decisión de adoptar este modelo organizativo fue justificada por los dirigentes de Podemos como una necesidad impuesta por el intenso calendario electoral al que tuvo que enfrentarse el nuevo partido meses después de su creación. En efecto, entre 2015 y 2016 se celebraron elecciones municipales, autonómicas y dos elecciones generales. La conexión entre el modelo organizativo elegido en 2014 y el calendario electoral de 2015 fue expuesta de forma explícita por Errejón ${ }^{11}$ :

Nuestra propuesta política está diciendo que hay una ventana de oportunidad profunda y estrecha que se puede cerrar, así que tenemos que crear una

11 Errejón, Í. (2014). Vamos a construir una maquinaria de guerra electoral. Público, 23-10-2014. Disponible en: https://bit.ly/2FunhX2. 
organización muy democrática, que esté en manos de los militantes, pero también, si me permites, una máquina de guerra electoral extraordinariamente rápida y eficaz, y esto no es sólo un análisis político. Va de la mano con un diseño organizativo.

El contexto político que rodeó la creación de FI en 2016 era muy diferente de la España de 2014, lo que explica parcialmente las diferencias organizativas entre ambos partidos. En 2016, el potencial electoral del Frente de Izquierda (creado en 2009 por el Partido de Izquierda de Jean-Luc Mélenchon y el Partido Comunista, además de otras formaciones más pequeñas) parecía agotado. Después de haber obtenido un resultado considerable en las elecciones presidenciales de 2012 (11\%), el Frente de Izquierda obtuvo menos del $5 \%$ de los votos en las elecciones regionales de 2015. En 2016, la vida política francesa estaba dominada por el miedo a los atentados terroristas, la hegemonía del discurso del Frente Nacional y la adopción de una línea política neoliberal y securitaria por parte del gobierno de François Hollande y Manuel Valls. En este contexto difícil para la izquierda, Mélenchon creó FI el 10 de febrero de 2016. La fundación de FI no vino precedida por un movimiento social horizontalista como en el caso de Podemos ni se produjo justo antes de una elección, lo que dio a sus creadores un amplio margen de maniobra para definir el modelo organizativo del nuevo partido. Por lo tanto, la estructura de FI es la consecuencia de las decisiones de Mélenchon y sus colaboradores.

\section{ENTRE AUTOORGANIZACIÓN Y JERARQUÍA: LOS MODELOS ORGANIZATIVOS DE PODEMOS Y LA FRANCIA INSUMISA}

Como se ha señalado previamente, los rasgos principales del modelo organizativo de Podemos fueron establecidos en su primer congreso fundacional, conocido como Vistalegre 1. El congreso, que tuvo lugar entre los meses de septiembre y noviembre de 2014, estuvo compuesto de dos partes: un encuentro físico y una votación por internet en la que participaron más de 100000 personas. Se enfrentaron dos proposiciones organizativas. Por un lado, los eurodiputados Pablo Echenique, Teresa Rodríguez y Lola Sánchez, así como el partido Izquierda Anticapitalista (integrado en Podemos), propusieron un modelo organizativo en el que los círculos tomarían la mayoría de las decisiones. Por otro lado, Pablo Iglesias y la mayoría de los fundadores del partido (entre ellos Ínigo Errejón, Carolina Bescansa y Juan Carlos Monedero) defendieron un modelo de partido clásico. La segunda opción obtuvo el $80 \%$ de los votos, por lo que el nuevo partido nació como una organización compuesta por una dirección estatal poderosa y direcciones territoriales relativamente autónomas. Los círculos fueron concebidos como espacios necesarios 
para promover la movilización ciudadana, pero no se les dio ningún poder de decisión sobre la orientación política del partido, la elección de su dirección o la selección de candidatos a las elecciones. Además, el Documento organizativo propuesto por Pablo Iglesias y aprobado en Vistalegre I también excluyó la posibilidad de seleccionar por sorteo una parte de la dirección del partido, subrayando la «eficacia» del equipo encabezado por él mismo ${ }^{12}$. No obstante, el modelo organizativo aprobado en Vistalegre I incluyó innovaciones importantes en relación con otros partidos políticos, como la elección por primarias por internet de todos los dirigentes y candidatos, un sistema de revocatorios y de consultas telemáticas a la militancia y un código ético exigente, que estableció un límite salarial para los dirigentes, parlamentarios y personal contratado de Podemos.

Los documentos organizativos aprobados en los congresos de Vistalegre I (noviembre 2014) y Vistalegre II (febrero 2017) determinan que las personas inscritas en Podemos deciden mediante votaciones telemáticas la orientación política del partido, sus candidatos a las elecciones y sus direcciones territoriales ${ }^{13}$. Sin embargo, la mayoría de las votaciones y primarias han estado regidas por sistemas fuertemente mayoritarios, que atribuyen al candidato más votado la gran mayoría o la totalidad de los puestos en disputa. Este tipo de regulaciones ha llevado a analistas como el sociólogo Rodríguez López a denunciar una "lógica plebiscitaria» (2016). Rodríguez López considera que las primarias y las consultas telemáticas "fueron legados del "participacionismo" del $15 \mathrm{M}$, pero acabaron siendo poco más de un formalismo vacío". Por otro lado, las comisiones de Garantías Democráticas creadas para aplicar el Código Ético de Podemos y la resolución imparcial de conflictos perdieron la independencia relativa respecto a la dirección del partido que tuvieron en sus inicios ${ }^{14}$.

Dos de las propuestas organizativas que se presentaron en el congreso de Vistalegre II (febrero de 2017) incluían mecanismos para limitar el poder de la dirección del partido y reforzar instituciones de control como la Comisión de Garantías Democráticas. Aunque la mayoría de las personas inscritas que participaron en las votaciones apoyó alguna de estas propuestas, el sistema

12 Claro que Podemos (2014). Borrador de Principios Organizativos. Disponible en: http://bit.ly/2v4nPwA. Riveiro, A. (2014). Iglesias apuesta por un liderazgo único: «Tres secretarios generales no ganan a Rajoy y Sánchez». Eldiario.es, 18-10-2014. Disponible en: https://bit.ly/2YYCXtc.

13 Claro que Podemos (2014). Op. cit. Podemos (2017). Documento Organizativo. Disponible en: https://bit.ly/2HOfc0z.

14 Varios autores (2017). Una Comisión de Garantías independiente y eficaz, objetivo irrenunciable para Vistalegre 2. Disponible en: https://bit.ly/2TPF1om. 
mayoritario que rigió las votaciones y la ausencia de alianzas entre los sectores que promovían estas reformas tuvieron como consecuecnia la adopción de un modelo organizativo muy similar al de Vistalegre I (Podemos, 2017). Por lo tanto, las características organizativas identificadas en los párrafos precedentes siguieron vigentes en Podemos después de Vistalegre II.

El modelo organizativo de FI comparte la verticalidad de Podemos, pero también presenta rasgos diferentes. En una entrevista de 2017, Jean-Luc Mélenchon definió FI como un "movimiento», negando que se tratase de un partido. Además, Mélenchon afirmó que FI no es «vertical ni horizontal, sino gaseosa" (Ducros, 2017). Como en el caso de Podemos, la estructura inicial de FI estaba basada en una red de grupos locales creados libremente por ciudadanos anónimos. Estos "grupos de apoyo" — como fueron denominados al principio- eran coordinados a través de una plataforma telemática, gestionada por el equipo dirigente de FI e inspirada de la campaña de Bernie Sanders para las primarias del Partido Demócrata. En la Convención Nacional celebrada en Clermont-Ferrand en noviembre de 2017, FI estableció su estructura definitiva, que es muy diferente de las de la mayoría de los partidos políticos. FI no está formada por un conjunto de estructuras territoriales jerárquicas, sino por una red de grupos locales (rebautizados como "grupos de acción») y por un conjunto de "espacios» con funciones específicas: el Equipo Operacional, el Equipo de Programa, el Grupo Parlamentario, el llamado «Espacio de Luchas» y el Espacio Político.

Según la web de $\mathrm{FI}^{15}$, el Equipo Operacional «tiene la misión de llevar a cabo las tareas operacionales necesarias para las campañas del movimiento». Este equipo está formado por los responsables de diversas funciones específicas dentro de FI, como la coordinación de los grupos de acción y la creación de materiales para las campańas de comunicación. Por su parte, el Equipo de Programa «anima el trabajo programático de FI», elaborando argumentarios y formaciones para la militancia. El Grupo Parlamentario está compuesto por los diecisiete diputados del partido en la Asamblea Nacional, mientras que el denominado «Espacio de Luchas» tiene el objetivo de agrupar y apoyar a los militantes de FI que también pertenecen a sindicatos o asociaciones cuyos objetivos son compatibles con el programa de FI, El futuro en común (Mélenchon y La France Insoumise, 2016).

Finalmente, el Espacio Político reúne a los partidos políticos que se han integrado en FI (los «comunistas insumisos» - miembros del PCF que apoyan a FI-, el Partido de Izquierda, Ensemble y Nouvelle Gauche Socialiste). El

15 La France Insoumise (2017). Les espaces de la France insoumise. Disponible en: https://bit.ly/2TuhbcY. 
rechazo radical de la noción de partido por parte de los dirigentes de FI se manifiesta claramente en el siguiente documento de FI, dedicado al Espacio Político y publicado en la web de la organización ${ }^{16}$ :

Este movimiento no es un partido ni un cártel de partidos. Un partido está compuesto por miembros-cotizantes, organizados en estructuras territoriales y estructuras de toma de decisión formalizadas. Los partidos tienen su utilidad. FI no pretende sustituirlos. [FI] busca una forma de organización libre de relaciones de subordinación.

En FI, los principales puestos decisorios son ocupados por las personas que dirigieron la campaña presidencial de Jean-Luc Mélenchon en 2017, que no han sido elegidos por la militancia del partido. Por otro lado, la Carta que regula el funcionamiento de los grupos de acción señala que los grupos «disponen de autonomía de acción dentro del respeto del programa El futuro en común» ${ }^{17}$. Sin embargo, los grupos de acción no tienen ningún poder de control sobre el grupo parlamentario o capacidad de decisión sobre la orientación política de partido y la selección de candidatos para las elecciones, lo que constituye un importante elemento en común con los círculos de Podemos.

El sistema de selección de candidatos es probablemente el elemento que muestra más claramente las particularidades del modelo organizativo de FI, ya que reúne las diferentes lógicas que definen la estructura del partido: la ocupación de los principales puestos por el equipo de Mélenchon, la atribución de un poder limitado a los partidos integrados en FI y el uso del sorteo como sustituto de las votaciones por parte de la militancia. Según la web de la organización, el comité electoral está compuesto por varios integrantes del llamado "Espacio de Luchas», cuatro representantes de los partidos del Espacio Político y ocho coordinadores de grupos de acción seleccionados por sorteo. El comité es coordinado por tres dirigentes cercanos a Jean-Luc Mélenchon.

En relación con la justificación estratégica o teórica del modelo organizativo elegido por la dirección de FI, la comparación con Podemos es particularmente interesante. En el caso de FI, la decisión de construir un tipo de organización política radicalmente distinta de los partidos tradicionales no se ha justificado por elementos coyunturales (como el ciclo electoral fue utilizado para justificar el modelo jerárquico en el caso de Podemos), sino que ha

16 La France Insoumise (2017). L”espace politique. Disponible en: https://bit. ly/2WisMgV.

17 La France Insoumise (2017). Charte des groupes d"action de la France insoumise. Disponible en: https://bit.ly/2CuGztq. 
estado desde el principio en el centro del proyecto político de FI. En efecto, Jean-Luc Mélenchon y otros dirigentes de FI han repetido que su proyecto no es "unir a la izquierda", como defendían el PCF y el candidato socialista a las elecciones presidenciales de 2017, Benoit Hamon, sino "federar al pueblo» ${ }^{18}$. La relación entre el proyecto de "federar al pueblo" y el modelo organizativo adoptado por FI se explica de forma explícita en su página web ${ }^{19}$ :

La idea no es unir a los partidos existentes «de izquierda» —algunos de los cuales se han comprometido en la aplicación de políticas que ceden a las presiones de la oligarquía financiera-. FI pretende federar al pueblo, hacer de él el actor principal de nuestra sociedad y favorecer su autoorganización. [FI] tiene la vocación de ser el movimiento del que el pueblo se apropia para derribar a la oligarquía y tomar el poder.

\section{LA ESTRUCTURA DE PODEMOS Y LA FRANCIA INSUMISA: PARECIDOS Y SEMEJANZAS}

El análisis de los modelos organizativos de Podemos y FI muestra un punto en común importante entre ambas formaciones: la creación de una amplia red de grupos locales de militantes que disponen de autonomía para autoorganizarse y llevar a cabo campańas y acciones para apoyar el partido, pero no tienen ningún poder de decisión sobre la orientación política de la organización o la selección de candidatos. Sin embargo, son más importantes las diferencias entre los modelos organizativos de Podemos y FI. Podemos ha adoptado una estructura partidista clásica, compuesta por órganos de dirección territoriales, acompañada de algunos elementos organizativos innovadores como las primarias telemáticas y un Código Ético exigente. Por su parte, FI tiene una estructura muy diferente de los partidos tradicionales, compuesta por un conjunto de «espacios» con funciones específicas en lugar de estructuras territoriales con autoridad propia. Ambos partidos presentan una tendencia a la oligarquización, pero esta no puede considerarse como un rasgo del populismo de izquierdas, ya que es una característica de los partidos políticos en general, como señaló Michels (1914) hace más de un siglo.

Como se ha explicado anteriormente, las decisiones organizativas de FI parecen estar estrechamente ligadas a la adopción de una estrategia política populista. Por el contrario, en el caso de Podemos la jerarquización del partido

18 Mélenchon, J. L. (2016). Mon ennemi, c”est l"oligarchie !. L”Obs, 29-4-2016. Disponible en: https://bit.ly/2Q3gBRu.

19 La France Insoumise (2017). L"espace politique. Disponible en: https://bit.ly/2WisMgV. 
a partir del congreso de Vistalegre I es una consecuencia de la priorización total por parte de la dirección del partido de los objetivos electorales, no del carácter populista de Podemos. Por otro lado, tanto en Podemos como en FI, otra razón que probablemente explica las decisiones organizativas de la dirección es el deseo de mantenerse en el poder, un rasgo común a la mayoría de las organizaciones políticas. En consecuencia, el análisis comparado de los modelos organizativos de Podemos y FI no permite establecer ninguna conclusión general sobre la relación entre el populismo de izquierda y la organización interna de los partidos.

\section{CONCLUSIONES}

El populismo de izquierda se ha convertido en un fenómeno central en la política europea durante los últimos años, pero ha sido analizado con menos frecuencia que el populismo de derecha radical. La presente investigación contribuye a colmar este vacío mediante el análisis comparado de Podemos y FI, dos casos paradigmáticos de partidos populistas de izquierda en Europa. El análisis empírico del discurso y la organización interna de ambas formaciones ha permitido obtener conclusiones respecto a los casos estudiados, que ayudan a identificar mejor algunos rasgos del populismo de izquierda.

El análisis de Podemos y FI ha permitido alcanzar dos hallazgos. Primero, ambos partidos defienden un populismo «inclusivo» en las tres dimensiones identificadas por Mudde y Rovira Kaltwasser (2013): las dimensiones material, política y simbólica. En efecto, los dos partidos defienden políticas económicas keynesianas opuestas a las políticas de austeridad (dimensión material), proponen mecanismos de participación política directa (dimensión política) y definen el pueblo en términos no étnicos o culturales (dimensión simbólica). La orientación ideológica progresista parece determinar el carácter inclusivo del populismo practicado por estos partidos. No obstante, la inclusión de la población migrante en el concepto de pueblo es más explícita en el caso de Podemos y los discursos de ambos partidos presentan también diferencias relacionadas con el contexto político y la historia política de la izquierda en España y Francia.

En segundo lugar, el análisis de la organización interna de Podemos y FI muestra un solo punto en común entre ambos partidos: la creación de una red de grupos locales de apoyo que no tienen capacidad de decisión respecto a la orientación política del partido, la elección de dirigentes y la selección de candidatos. Por lo demás, las estructuras de ambas organizaciones son muy distintas: Podemos tiene una estructura jerárquica clásica similar a la de los partidos tradicionales, mientras que FI presenta una estructura original, pero 
que comparte con los partidos tradicionales la concentración del poder en un grupo reducido de individuos (oligarquización). El hecho de que tanto Podemos como FI presenten una tendencia a la oligarquización no implica que este sea un rasgo específico del populismo de izquierda, ya que es una característica de los partidos políticos en general. Este resultado refuerza respecto a la organización interna de los partidos la posición mayoritaria de la literatura sobre las relaciones entre populismo y democracia: no se puede establecer un modelo general de relación entre ambos. De la misma manera, el análisis realizado en el presente artículo no permite afirmar la existencia de un modelo organizativo propio del populismo de izquierda.

La ausencia de un modelo organizativo preciso ligado al populismo de izquierda implica que sería concebible un partido populista de izquierda que adopte una estructura más horizontal que la de los partidos políticos clásicos, estableciendo mecanismos para combatir la oligarquización y la burocratización. Algunos de estos mecanismos podrían ser la obligatoriedad de elecciones primarias con sistemas proporcionales para la elección de todos los dirigentes y candidatos del partido, la revocabilidad los cargos, la introducción de referendos internos obligatorios para la toma de decisiones importantes en el seno de la organización y la creación de órganos independientes que garanticen el cumplimiento de las normas internas y la resolución de conflictos.

\section{Bibliografía}

Adell Argilés, R. (2011). La movilización de los indignados del 15M: aportaciones desde la sociología de la protesta. Sociedad y Utopía, 38, 141-170.

Alba Rico, S. (2015). Islamofobia. Nosotros, los otros, el miedo. Madrid: Más Madera.

Arditi, B. (2011). La política en los bordes del liberalismo. Barcelona: Editorial GEDISA.

Castańo, P. (2016). Parecidos y diferencias entre Nuit Debout y el 15M. Eldiario.es, 11-42016. Disponible en: https://bit.ly/2FYHtiK.

— (2017). Mélenchon et l'immigration: entre convictions et ambigüités. Ballast. Disponible en: https://bit.ly/2OYnXXt.

- (2018). Populism and Democracy. Revista Internacional de Sociología, 76 (4), 2-8. Disponible en: https://doi.org/10.3989/ris.2018.76.4.18.089.

Birnbaum, P. (2017). Les «gens» contre «"oligarchie»: le discours de La France insoumise. Cités, 72 (4), 163-173. Disponible en: https://doi.org/10.3917/cite.072.0163.

Borreca, R. (2014). Political Crisis in Greece and Italy: a comparative analysis of SYRIZA and 5 Stars Movement. Ponencia presentada en la PSA 64th Annual International Conference (Manchester, 14-16 de abril de 2014).

Bréville, B. (2017). Embarras de la gauche sur l"immigration. Le Monde Diplomatique, 4, 14-14.

Casero-Ripollés, A., Sintes-Olivella, M. y Franch, P. F. (2017). The Populist Political Communication Style in Action: Podemos"s Issues and Functions on Twitter During the 2016 
Spanish General Election. American Behavioral Scientist, 61 (9), 986-1001. Disponible en: https://doi.org/10.1177/0002764217707624.

Crabtree, J. (1999). Populist seduction in Latin America: The Ecuadorian experience. Research in International Studies, Latin America Series. Ohio: Ohio University Center for International Studies.

De la Torre, C. (2013). In the Name of the People: Democratization, Popular Organizations, and Populism in Venezuela, Bolivia, and Ecuador. European Review of Latin American and Caribbean Studies, 95, 27-48. Disponible en: https://doi.org/10.18352/erlacs.9229.

- y Peruzzotti, E. (2008). El regreso del populismo. En C. de la Torre y E. Peruzzotti (eds.). El Retorno Del Pueblo. Populismo y Nuevas Democracias en América Latina (pp. 11-19). Quito: FLACSO.

Ducros, C. (2017). Mélenchon: le but de La France insoumise "n"est pas d"être démocratique mais collectif». Le Figaro, 17-10-2017. Disponible en: https://bit.ly/2GGybLV.

Errejón, I. (2011). La lucha por la hegemonia durante el primer gobierno del MAS en Bolivia (2006-2009): un análisis discursivo. Madrid: Universidad Complutense de Madrid. (2015). We the People. El 15-M: ¿un populismo indignado? ACME 14, 124-156.

Fassin, É. (2017). La gauche et la stratégie populiste. Après-Demain, 3, 12-13.

Fourquet, J. (2017). Sur la gauche radicale: le vote Mélenchon. Commentaire, 159 (3), 535542. Disponible en: https://doi.org/10.3917/comm.159.0535.

Franzé, J. (2017). La trayectoria del discurso de Podemos: del antagonismo al agonismo. Revista Española de Ciencia Política, 44, 219-246. Disponible en: https://doi. org/10.21308/recp.44.09.

Frei, R. y Rovira Kaltwasser, C. (2008). El populismo como experimento político: historia y teoría política de una ambivalencia. Revista de Sociología, 22, 117-140. Disponible en: https://doi.org/10.5354/0719-529X.2008.14485.

Freidenberg, F, (2008). El flautista de Hammelin: liderazgo y populismo en la democracia ecuatoriana. En C. De la Torre y E. Peruzzotti (eds.). El Retorno Del Pueblo: Populismo y Nuevas Democracias en América Latina (pp. 185-233). Quito: FLACSO.

Gales, A. (2015). Mélenchon, de la Gauche au Peuple 1/2. Ballast. Disponible en: https://bit. ly/2QQzIn3.

Gamarra, E. A. (2008). Bolivia: Evo Morales and Democracy. Constructing Democratic Governance in Latin America, 3, 124-151.

Garea, F. (2011). Apoyo a la indignación del 15-M. El País, 5-6-2011. Disponible en: https:// bit.ly/2TTHUEE.

Grueso, S. M. y Sánchez, J. (2016). Podemos no es el 15M, pero sin el 15M no habría existido. Eldiario.es, 12-5-2016. Disponible en: https://bit.ly/2unxXAh.

Hernández-Carr, A. (2011a). ¿La hora del populismo? Elementos para comprender el «éxito» electoral de Plataforma per Catalunya. Revista Española de Investigaciones Sociológicas, $153,47-74$.

- (2011b). La derecha radical populista en Europa: discurso, electorado y explicaciones. Revista Española de Investigaciones Sociológicas, 136 (1), 141-159.

Kioupkiolis, A. (2016). Podemos: the ambiguous promises of left-wing populism in contemporary Spain. Journal of Political Ideologies, 21 (2), 99-120. Disponible en: https://doi. org/10.1080/13569317.2016.1150136. 
— y Katsambekis, G. (2018). Radical Left Populism from the Margins to the Mainstream: A Comparison of Syriza and Podemos. En O. G. Agustín y M. Briziarelli (eds.). Podemos and the New Political Cycle (pp. 201-226). London: Palgrave Macmillan,Cham. Disponible en: https://doi.org/10.1007/978-3-319-63432-6_9.

Laclau, E. (2005). La razón populista. Buenos Aires: Fondo de Cultura Económica.

- y Mouffe, C. (2001). Hegemony and socialist strategy: Towards a radical democratic politics. Londres: Verso.

Le Gal, T. (2017). Mélenchon 2017 VS 2012, le candidat tient-il le même discours sur l"immigration? 20 Minutes, 9-4-2017. Disponible en: https://bit.ly/2ujrjep.

Levitsky, S. y Roberts, K. M. (eds.) (2011). The Resurgence of the Latin American Left. Baltimore: The Johns Hopkins University Press.

Lindekilde, L. (2014), "Discourse and Frame Analysis: In-Depth Analysis of Qualitative Data in Social Movement Research". En D. Della Porta (ed.). Methodological Practices in Social Movement Research (pp. 195-227). Oxford: Oxford University Press. Disponible en: https://doi.org/10.1093/acprof:oso/9780198719571.003.0009.

Marzolf, H. y Ganuza, E. (2016). ¿Enemigos o colegas? El 15M y la hipótesis Podemos. EMPIRIA,33,89-110. Disponible en: https://doi.org/10.5944/empiria.33.2016.15865.

Mélenchon, J. L. (2010). Qu"ils s"en aillent tous! Paris: Flammarion.

- (2014). L"Ere du peuple. Paris: Fayard.

— y Endeweld, M. (2016). Le choix de l"insoumission. Paris: Le Seuil.

- y La France Insoumise (2016). L"Avenir en commun. Le programme de la France insoumise et son candidat Jean-Luc Mélenchon. Paris: Le Seuil.

Michels, R. (1914). Les Partis Politiques: Essai sur les Tendances Oligarchiques des Démocraties. París: FB et C Limited.

Mouffe, C. (2005). On the political. Abingdon; New York: Routledge.

Mudde, C. (2004). The populist zeitgeist. Government and Opposition, 39, 541-563. Disponible en: https://doi.org/10.1111/j.1477-7053.2004.00135.x.

— (ed.) (2016). The Populist Radical Right: A Reader. Abingdon; Nueva York: Routledge. Disponible en: https://doi.org/10.4324/9781315514574.

— y Rovira Kaltwasser, C. (2013). Exclusionary vs. Inclusionary Populism: Comparing Contemporary Europe and Latin America. Government and Opposition, 48, 147-174. Disponible en: https://doi.org/10.1017/gov.2012.11.

Panizza, F. (2008). Fisuras entre populismo y democracia en América Latina. Stockholm Review of Latin American Studies, 3, 81-93.

Pasquino, G. (2008). Populism and Democracy. En D. Albetazzi y D. McDonnell (eds.). Twenty-First Century Populism (pp. 15-29). London: Palgrave Macmillan. Disponible en: https://doi.org/10.1057/9780230592100_2.

Peruzzotti, E. (2013). Populism in democratic times: populism, representative democracy, and the debate on democratic deepening. En C. de la Torre y C. J. Arson (eds.). Latin American Populism in the Twenty-First Century (pp. 61-85). Baltimore; Washington: Johns Hopkins Universty Press; Woodrow Wilson Center Press.

Prat, C. R.-A. de (2015). Semejanzas y diferencias entre el Movimento 5 stelle y Podemos. Società Mutamento Politica, 6 (11), 51-74. 
Repoll, J. (2010). Política y medios de comunicación en Argentina: Kirchner, Clarín y la Ley. Andamios, 7 (14), 35-67. Disponible en: https://doi.org/10.29092/uacm.v7i14.100.

Rodríguez López, E. (2016). La política en el ocaso de la clase media. Revista Contexto. Disponible en: https://bit.ly/2U1GEhV.

Semenzin, S. (2015). La comunicación política en tiempos de crisis: una comparación entre Italia y Espańa. Documentación de las Ciencias de la Información, 38, 83-102. Disponible en: https://doi.org/10.5209/rev_DCIN.2015.v38.50810.

Thomassen, L. (2016). Hegemony, Populism and Democracy: Laclau and Mouffe Today (Review Article). Revista Española de Ciencia Politica, 40, 161-176.

Uribe Otalora, A. (2017). El populismo como vanguardia del desencanto político en Europa: el fenómeno «Podemos» en España. Revista de Estudios Politicos, 177, 213-255. Disponible en: https://doi.org/10.18042/cepc/rep.177.07.

Weyland, K., Madrid, R. L. y Hunter, W. (2010). Leftist governments in Latin America: successes and shortcomings. New York: Cambridge University Press. Disponible en: https://doi. org/10.1017/CBO9780511778742. 